\title{
Revisional Surgeries of Laparoscopic Sleeve Gastrectomy
}

This article was published in the following Dove Press journal:

Diabetes, Metabolic Syndrome and Obesity: Targets and Therapy

\section{Siyuan $\mathrm{Li}^{*}$ \\ Siqi Jiao* \\ Siwei Zhang* \\ Jiangjiao Zhou (D)}

Department of General Surgery, The Second Xiangya Hospital, Central South University, Changsha, Hunan, 4I00II, People's Republic of China

*These authors contributed equally to this work
Correspondence: Jiangjiao Zhou Department of General Surgery, The Second Xiangya Hospital, Central South University, No. 139 Middle Renmin Road, Changsha, Hunan, 4I00II, People's Republic of China

Email zhoujiangjiao@csu.edu.cn

\begin{abstract}
Bariatric surgery has become increasingly common due to the worldwide obesity epidemic. A shift from open to laparoscopic surgery, specifically, laparoscopic sleeve gastrectomy (LSG), has occurred in the last two decades because of the low morbidity and mortality rates of LSG. Although LSG is a promising treatment option for patients with morbid obesity due to restrictive and endocrine mechanisms, it requires modifications for a subset of patients because of weight regain and tough complications, such as gastroesophageal reflux, strictures, gastric leak, and persistent metabolic syndrome., Revision surgeries have become more and more indispensable in bariatric surgery, accounting for $7.4 \%$ in 2016. Mainstream revisional bariatric surgeries after LSG include Roux-en-Y gastric bypass, repeated sleeve gastrectomy, biliopancreatic diversion, duodenal switch, duodenal-jejunal bypass, one-anastomosis gastric bypass, single anastomosis duodeno-ileal bypass (SAID) and transit bipartition. This review mainly describes the revisional surgeries of LSG, including the indication, choice of surgical method, and subsequent effect.
\end{abstract}

Keywords: bariatric surgery, laparoscopic sleeve gastrectomy, revisional surgery

\section{Introduction}

As a serious worldwide public health problem, obesity is associated with many chronic diseases. In fact, more than 600 million of adults were affected by obesity in 2014, and the prevalence of obesity has doubled since $1980 .^{1}$ Bariatric surgery is a highly effective and durable therapy for losing weight and performed on individuals with severe obesity. In common bariatric operations, laparoscopic sleeve gastrectomy (LSG) is well known for its perceived technical simplicity, feasibility, and safety. Initially, LSG was a component of biliopancreatic diversion with duodenal switch (BPD-DS). Subsequently, LSG has become the first stage in a twostaged operation in patients with severe obesity. Given that short-term weight loss is guaranteed in the first-stage LSG, the second stage is often discontinued. LSG has become a stand-alone primary bariatric procedure. ${ }^{2}$ In 2014 , LSG was the most common performed procedure and has maintained its predominance in $2016(\mathrm{~N}=$ $340,550 ; 53.6 \%){ }^{3}$ LSG can help improve metabolic syndromes, such as diabetes and hypertension, and it has the short-term satisfying outcomes of weight loss. ${ }^{4}$ However, long-term failure rates are up to $64 \%{ }^{5}$ Considering the long-term weight recurrence and occurrence of complications, revisional surgery is an indispensable part after LSG.

The American Society for Metabolic and Bariatric Surgery (ASMBS) categorizes reoperative surgery into corrective, reversal, and conversion procedures. ${ }^{6}$ 
Corrective procedures are applied to a poorly constructed initial operation or the treatment of complications. Reversal procedures, as operations for restoring normal gastrointestinal anatomy, are essential for stubborn nutritional deficiencies or unbearable psychological issues. Conversion is the process of changing to another bariatric procedure for complications and inadequate response.

Currently, no set criteria for assessing the success or failure of bariatric surgery is available, and thus the necessity for revisional bariatric surgery is difficult to define. The most common indications for reoperation may be the inadequate control of weight or diabetes and occurrence of complications.

\section{Revisional Surgeries for Weight Regain}

Weight regain (WR) is defined as regaining weight to achieve a BMI $>35 .^{7}$ Approximately $14 \%$ of patients ${ }^{8}$ cannot maintain weight loss after bariatric surgery, and condition leads to the reappearance of obesity-related complications. Additionally, WR can have a devastating psychological effect, which lead to frustration, anger, and even depression, as patients feel that they failed their last option. ${ }^{9}$

Several factors contribute to WR. First, although the optimal bougie size is suggested to be $32 \mathrm{~F}-36 \mathrm{~F},{ }^{10}$ the impact of bougie size on weight loss after sleeve gastrectomy (SG) remains controversial. Many studies have suggested that a thin bougie may be a protective factor against post-sleeve gastrectomy weight regain. ${ }^{11-13}$ As we know, LSG is a restrictive operation that requires removal of most of the fundus, body and antrum of the stomach under the guidance of a probe to reduce the volume of the stomach. There is a study showing that the sleeve dilatation might contribute to weight regain, which probably because there is an incompletely excised fundus and then increasingly distend and release larger amounts of ghrelin. However, most of the current research results in this area are not very convincing ${ }^{14}$ and the cause of gastric sleeve expansion is still under further study. ${ }^{13}$ For WR that may be caused by sleeve expansion, banded LSG (BLSG) with a MiniMizer ${ }^{\circledR}$ ring to add restriction in LSG might be an effective preventive measure. ${ }^{15,16}$ Moreover, a high residual gastric volume and gastric dilation are significantly and positively correlated with WR. ${ }^{17-19}$ As for the antral dilation, the research from Emmanuel Disse shows that compared with the group without gastric dilatation, although the total gastric volume, the volume of the gastric tube, and the diameter of the gastric tube were remarkably higher in the group with gastric dilatation, the volume of the antrum was similar between the groups. ${ }^{20}$ Besides, whether to retain the gastric antrum and the size of the retention does not seem to have a major impact on WR. ${ }^{21,22}$ In addition to anatomical and physiological factors, WR is significantly associated with older age 5 years after LSG. ${ }^{8}$ Many studies previously confirmed a positive effect of younger age on weight loss after bariatric surgery, ${ }^{23-26}$ and postoperative loss-of-control eating is associated with decreased rate of weight loss after bariatric surgery. ${ }^{27-29}$ Additionally, different groups studied the effect of pregnancy on weight loss following bariatric surgery and showed conflicting results. ${ }^{30-32}$ Ashraf A found that the earlier the pregnancy is, the worse the effect of weight loss is. ${ }^{8}$ Other predictors, such as ghrelin, ${ }^{33}$ serotonin, ${ }^{34}$ mood, ${ }^{35}$ and follow-up support ${ }^{13,36}$ have been introduced.

Weight-reduction measures are essential. The antiobesity drug pipeline is active and develops several new agents, including GLP-1 receptor agonists (such as semaglutide, which is being developed in oral formulations), dual-action GLP-1, glucagon receptor agonists, amylin mimetics, triple gut hormone agonists, and anti-obesity vaccines. ${ }^{37}$ Traditionally, a conversion to duodenal switch (DS) or Roux-en-Y gastric bypass (RYGB) has been the standard of revision. DS is appropriate when the original operation is the first part of the entire operation, ${ }^{38,39}$ whereas RYGB is suitable for patients with the complications of gastroesophageal reflux disease (GERD). However, compared with reLSG, these two types of surgery methods have higher incidence rates of postoperative complications. ${ }^{40}$ Compared with malabsorptive procedures, this re-intervention offers several advantages, such as increased restriction; decreased gastric output; decrease in the incidence of dumping syndrome by preserving the pylorus; decreased risk of anemia, osteoporosis, and protein and vitamin deficiency (except B12 and thiamine); and reduced operative time. ${ }^{41}$ According to the radiological studies of Braghetto et $\mathrm{al}^{42-45}$, a $250 \mathrm{~cm}^{3}$ threshold measured through the $\mathrm{CT}$ scan volume method may be a possible indication of reLSG, also known as fundectomy, and a residual volume below this threshold prompts conversion to a malabsorptive procedure. In recent years, single-anastomosis duodeno-ileal bypass (SADI), oneloop operation, has gained more attention because of its 
simplified technique and comparable or even better result than conventional operations. ${ }^{46,47}$

With regard to weight loss outcomes in short- and midterm, BPD/DS appears to be superior to RYGB and Resleeve gastrectomy (ReSG). Given that LSG has been introduced as the restrictive part of BPD, BPD/DS seems to be the most appropriate second procedure, although the latter carries an increased risk of deficiencies, protein malnutrition, and intestinal bacterial overgrowth. Still, the fact that RYGB is technically less demanding than $\mathrm{BPD} / \mathrm{DS}$, has lower complication rates, and is less malabsorptive inclines many surgeons to opt to perform RYGB. Many documents have indicated that Re-LSG is a feasible and safe surgical approach for weight regain post-LSG, remains effective for $53.8 \%$ after 5 years, and is best used when the gastric pouch is extremely large or when the gastric tube is dilated after original LSG. ${ }^{44,48-51}$ Besides, SADI extends the common limb length and reduce the long-term complication rate, while $\mathrm{BPD} / \mathrm{DS}$ performs a better outcome than SADI when the starting BMI is high. $^{46,47}$ Further trials and meta-analyses of ReSG are necessary to prove the efficiency and compare the outcomes of Re-LSG with those of RYGB, DS, or SADI. ${ }^{40,46}$

\section{Revisional Surgeries for T2DM Relapse}

Many studies have demonstrated that LSG is effective in significantly resolving or alleviating obesity-related comorbidities, such as type 2 diabetes mellitus (T2DM), hypertension, and dyslipidemia and reducing the use of drugs in addition to weight loss. ${ }^{52,53}$ The resolution rates of DM vary from $26 \%$ to $66 \%$ in the literature. ${ }^{53-55}$ Currently, the best predictors of improvement in blood glucose control after bariatric surgery are decrease in waist circumference, better-controlled diabetes, and decrease in triglyceride levels at baseline. ${ }^{56,57}$ Some studies have suggested that S100A8/A9 and IL- $6,{ }^{58}$ diabetes duration, and $\% \mathrm{EWL}^{59}$ are related to persistent diabetes status post-surgery. Although T2DM after relapse is often milder, medical treatment is still needed in most cases (the amount of medicine required is usually less than the preoperative requirement). ${ }^{60}$ Along with weight loss, incretins may play a role in diabetes remission after bariatric surgery. $^{61}$ Blocking the glucagon-like peptide-1 (GLP-1) receptor with exendin9-39 reverses the effect of bariatric surgery on $\beta$-cell function and glucose tolerance. ${ }^{62}$ The inhibitors of dipeptidyl peptidase-4 (DPP-4), the enzyme that inactivates GLP-1, are well tolerated and weightneutral and thus commonly used for the treatment of T2DM. $^{63}$ Whether the addition of DPP-4 inhibitors improve glucose control after RYGB and when GLP-1 levels are elevated and DPP-4 activity decreased.

Revision options are to redo $\mathrm{SG}$ or to convert $\mathrm{SG}$ to either RYGB or DS. Regarding their effects on residual T2DM, RYGB can induce considerable and persistent improvement in MetS prevalence in T2DM patients with obesity. ${ }^{59,64,65}$ Aleassa showed clinical remission at a rate of $23.1 \%$ and improvement of $30.8 \%$ in patients converted to RYGB. ${ }^{66}$ Recently, many studies ${ }^{67-69}$ have shown that $\mathrm{SG}$ results in the same remission rates of metabolic syndrome as RYGB, although LSG seems to be inferior to laparoscopic RYGB with regard to the control of hypertension and high-density lipoprotein cholesterol ${ }^{68}$ partly due to the greater weight loss of RYGB..$^{64,67,70}$ In Gautier's series, patients with persistent T2DM after SG show improvement after conversion to RYGB. ${ }^{51} \mathrm{Ali}$ and his colleagues divided T2DM into three validated severity stages for the first time for selection based on evidencebased procedures. $^{71}$ In mild T2DM (IMS score $\leq 25$ ) and severe T2DM (IMS score $>95$ ), both procedures significantly improved T2DM. However, in an intermediate group, RYGB was significantly more effective than SG likely because of the more pronounced neurohormonal effects of RYGB. Adding a DS might also be a good option based on the mechanism of foregut bypass. ${ }^{72}$ However, LSG is still a favorable choice for T2DM treatment in morbid patients with obesity and short duration of DM and good beta cell preserve. ${ }^{73,74}$

\section{Revisional Surgeries for Complications of LSG Revisional Surgeries for GERD}

The pathophysiological mechanisms predisposed to gastroesophageal reflux disease (GERD) in obesity include increased intra-abdominal pressure, impaired gastric emptying, decreased lower esophageal sphincter (LES) pressure, and the high frequency of transient LES relaxation. Thus, obesity itself is an important risk factor for GERD.

The connection between LSG and GERD has always been a focus of debate among scholars. Some researchers think that LSG is an effective method of metabolic surgery and can improve GERD (especially mild GERD), whereas some studies pointed out that the incidence of GERD after LSG was higher than that after bariatric surgery. ${ }^{75}$ 
Rebecchi analyzed 18 studies that investigated 45 patients followed up for at least 12 months after surgery. ${ }^{76}$ Six of these studies showed increased prevalence in GERD after SG, and 9 studies showed a decreased prevalence, leaving a controversy on LSG outcomes.

The physiological factors of LSG causing GERD are manifold. The possible physiological and anatomical changes that cause postoperative GERD aggravation or de novo GERD include the formation of a hiatal hernia (HH) caused by the sleeve, change in His angle, destruction of the lower esophageal sphincter, development of high intrathoracic pressures, decreasing volume, and increasing pressure in the stomach. ${ }^{77,78}$ Csendes performed a prospective study based on the sequential clinical, endoscopic, and histologic evaluations of the foregut after LSG and confirmed the negative impact of LSG causing GERD. ${ }^{79}$ By contrast, in long-term follow-up after LSG, changes in His angle and stomach volume, increase in stomach compliance, weight-loss and acceleration of gastric emptying that improve or resolute reflux symptoms. ${ }^{80}$

Given the complexity of the diagnosis of GERD and the subjectivity of patient experience, ${ }^{81}$ as well as the lack of objective indicators after surgery, evidence of the correlation between GERD and LSG is still lacking. Some scholars have attempted to determine the relationship between LSG and GERD by the pH monitoring of gastrooesophageal reflux before or after LSG. ${ }^{82,83}$ However, short follow-up time and inaccurate testing methods increase confusion about this problem.

Esophagogastroscopy is considered a routine diagnostic test prior to bariatric surgery and used in detecting asymptomatic benign-like $\mathrm{HH}$ and premalignant or malignant lesions. ${ }^{84} \mathrm{HH}$ contributes to the pathogenesis of GERD, ${ }^{85}$ and thus LSG with concomitant hiatal hernia repair (HHR) is seemingly beneficial to patients with GERD. However, an increasing amount of evidence shows that HHR is inefficient in preventing the occurrence and development of GERD after LSG. ${ }^{86-88}$ For patients with obesity, whether receiving LSG and routine preoperative endoscopy ${ }^{78,89,90}$ and HHR are necessary requires additional prospective studies. The good news is that LSG with anti-reflux fundoplication emerges as a new valid option for patients with GERD. ${ }^{91}$

Presently, PPIs can be used in treating mild patients. Other patients are suggested to undergo surgery treatment. The gold standard surgical approach for GERD is laparoscopic Nissen fundoplication plus crural closure. ${ }^{92}$ In addition, the Linx Reflux Management System, EndoStim LES Stimulation System, Esophyx ${ }^{\circledR}$, and MUSETM endoscopic fundoplication devices and the Stretta endoscopic ablation system are emerging techniques for treating this disease.

Some patients with proximal gastric pouch dilatation and refractory to PPI therapy without accepting revisional bariatric surgery can consider anterior fundoplication. ${ }^{93,94}$ For patients who are unsuitable for revision, $72 \%$ of 32 expert bariatric surgeons disagree that repairing the hiatal hernia might control symptoms according to the best practice guidelines in $2017,{ }^{95}$ although many scholars prefer HHR as a treatment for GERD. ${ }^{72,96,97}$

When PPIs are ineffective in relieving GERD symptoms, and RYGB is considered the optimal treatment approach in the absence of a correctable anatomic factor. ${ }^{98}$ In Guan's statistics, ${ }^{99}$ the pooled rate of revision due to GERD was $3.1 \%$. For postoperative patients with uncontrolled GERD, RYGB is the procedure of choice. ${ }^{91}$ After RYGB, the average esophageal acid exposure declines in a large percentage of individuals with increased acid exposure and DeMeester scores postoperation. ${ }^{100}$ The mechanism by which RYGB alleviates GERD symptoms probably accounts for the small volume of the new gastric pouch consisting of the cardia region of the stomach and for the disappearance of bile reflux, which impairs the reservoir capacity and promotes regurgitation. ${ }^{101}$ Conversion to RYGB cures patients from reflux well. In addition, few GERD cases treated with ligamentum teres cardiopexy (LTC) combined with the closure of the gastric crus. ${ }^{102}$ The principle is creating an artificial valve restoring the angle of His for the reduction of hernia and prevention of reflux. Securing the esophagogastric junction (EGJ) via LTC provides mobility with hepatic movements, which occur with breathing and diaphragmatic displacement. ${ }^{103}$ At present, the sample size of this technique is still relatively small and cannot be compared with that of RYGB. However, it is noteworthy that the symptomatology of GERD does not always disappear after RYGB treatment. As a trial reports, 23 of 80 GERD patients receiving RYGB maintained reflux after 6 months, especially in patients with previous gastric banding. ${ }^{104}$ With more postoperative complications, LTC should be avoided in LSG patients with GERD, BPD/DS, ${ }^{105,106}$ and Oneanastomosis gastric bypass (OAGB). ${ }^{107}$ Manabu Amiki had the same conclusion, that is, LBPD/DS or duodenojejunal bypass (DJB) as revision surgery appears to be effective for further weight loss in the medium term, and 
laparoscopic RYGB appears to be effective for GERD remission. ${ }^{108}$

\section{Revisional Surgeries for Strictures}

Gastric sleeve stenosis is one of the most frequent complications after LSG. In a review of the published literature regarding LSG for morbid obesity, the incidence of gastric stenosis (GS) varies from $0.7 \%$ to $4 \% .{ }^{109}$ Noticeably, many of the stenosis of LSG are underdiagnosed, which means that the real percentage is higher than reported in the literature.

Two different mechanisms contribute to GS: mechanical stenosis and functional stenosis. For one thing, anatomic stenosis is generally blamed on sharp angulations of the stapler, reinforcing sutures placed over the staple line, a bougie size that is too small, or hematomas and edema. For another, the functional obstruction always occurs by misalignment of the staples, alteration of the pouch architecture, the indentation of the incisura within the gastric lumen and an excess volume of stomach from the back wall which may produce tube twisting with an axial deviation. ${ }^{110,111}$

Chang et $\mathrm{al}^{112}$ improved their surgical techniques. Parallel first linear stapler firing at the antrum, making a mark with a $2 \mathrm{~cm}$ width at the level of the incisura angularis and leaving at least a $5 \mathrm{~mm}$ width of the fundus at the level of the gastroesophageal junction, prevent overnarrowing at frequent stenotic locations after LSG (the incisura angularis and gastroesophageal junction). For the most common phenomenon of GS, twisting, they fixed the greater curvature site of the sleeve gastric tube with retroperitoneal fat through suturing to maintain the axis of the whole tube and prevent possible axial distortion due to postoperative adhesion after the withdrawal of the calibrated orogastric tube. They emphasized that "standardized" LSG to prevent GS is extremely important. ${ }^{112}$ In the International Sleeve Gastrectomy Expert Panel Consensus Statement in 2012, a collective series of $>12,000$ SGs performed by 24 centers worldwide, maintaining symmetric lateral traction while stapling after mobilization and takedown of short gastric vessels reduce the potential for strictures. Using an appropriately sized bougie when stapling the incisura angularis can decrease stricture formation. ${ }^{10}$ The gastric stenosis post LSG presents classically with food dysphagia, nausea, vomiting, regurgitation, rapid weight loss or even staple line leaks after surgery. ${ }^{113}$

For this tough complication, a UGI contrast study should be conducted. If the results of this study are abnormal or if symptoms persist, an esophagogastroduodenoscopy should be performed with anticipation of performing a dilation. Repeated dilation can be performed as long as a patient demonstrates improvement in oral tolerance. The placement of a stent can be considered, although a stent is poorly tolerated by a patient due to pain and discomfort. Long-segment stenoses that do not respond to endoscopic techniques (most experts consider patients whose endoscopic dilation for 6 weeks has failed) ${ }^{10}$ require revisional surgery. The surgical revision options include laparoscopic RYGB, wedge gastrectomy, or seromyotomy. ${ }^{114}$ The first line of treatment for a stenosis is endoscopic dilatation using the Savary bougie, which is an effective, safe, and durable method for managing stenosis after LSG. Currently, laparoscopic RYGB creating a gastric pouch proximal to a stenosed gastric lumen remains the most popular and effective revisional surgery. Seromyotomy can be useful but carries a high rate of resulting in complications, such as gastric leak. Accurate technique with the parsimonious use of coagulation and possibly with the systematic use of an omental patch might lead to good results. ${ }^{115}$ Seromyotomy ${ }^{115}$ and median gastrectomy ${ }^{116}$ are alternative surgical procedures. Median gastrectomy is suitable for addressing persistent stenosis within the gastric sleeve located within the midbody. This approach has a low risk of leak in contrast to seromyotomy and preserves the gastric sleeve option without a need to convert to a gastric bypass. ${ }^{116}$

\section{Revisional Surgeries for Gastric Leak}

Gastric leak (GL) is one of the most serious complications after LSG and the second most common cause of death after bariatric surgery. ${ }^{117}$ The UK Surgical Infection Study Group defined "leak" as "the leak of luminal contents from a surgical join between two hollow viscera" or "a gastrointestinal leak in a suture line around the organ," laying the foundation for comparisons and clinical audits. ${ }^{118} \mathrm{GL}$ is considered "acute" if observed within 7 days of LSG, "early" if observed 1-6 weeks after LSG, "late" if observed after 6 weeks, and "chronic" if it has lasted $>12$ weeks. ${ }^{10}$ The clinical manifestations of leakage vary. Mild patients may only have imaging manifestations, whereas severe patients develop septic shock, multisystem organ failure, and even death.

The average rate of leaks in LSG is $1.5 \% .{ }^{119}$ The two main reasons for leaks are mechanical and ischemic factors. ${ }^{120}$ Mechanical tissular damages usually appear 
within 2 days of surgery, including stapler misfiring and direct tissue injuries. In addition, the longer the staple line is, the easier it is to cause leakage. Ischemic leaks occur on the 5th or 6th postoperative day, and most leaks after LSG is operated near the gastroesophageal junction, ${ }^{121,122}$ which is the "critical area" of ischemic pathogenesis. The major reason of ischemic leak may be the dissection of the greater curvature with the use of electrocautery or a LigaSure device, which causes gastric wall heat ischemia near the staple line. ${ }^{123}$

The consequences of GL are disastrous. Therefore, the early diagnosis of postoperative GL is particularly important. Patients with GL present clinical perspectives, including abdominal pain, fever, tachycardia, tachypnea, and increased white blood cell and C-reactive protein (CRP) levels. The earliest symptom is tachycardia in patients with early leak, whereas fever is the earliest symptom in patients with late leak. ${ }^{123}$ Endoscopy is the gold standard treatment for acute staple line leaks. Once gastric leak is diagnosed, surgical supportive treatment is essential. Most early gastric leaks can be resolved by endoscopic operations, such as endoscopic stent, fibrin sealant injection, percutaneous glue, and hemoclips. Moreover, several neoteric technologies, such as the Over-the-Scope Clip system, laparo-endoscopic gastrostomy decompression, and endoluminal vacuum therapy have emerged, but their long-term effectiveness needs evidence. ${ }^{124-126}$ In addition, GL treatment through endoscopic internal drainage coupled to prompt external drainage mobilization is controversial. ${ }^{127-129}$ Compared with other treatments, the management of leaks following LSG is more difficult and usually need endoscopic therapies. ${ }^{129}$ The two probable explanations are as follows: the mechanism of SG, specifically the creation of a high-pressure gastric tube associated often with a functional angular stenosis, and lack of standardization in the management of the fistula, particularly when an endoscopic approach is used. ${ }^{130}$

Revisional bariatric surgery is usually suitable for patients with chronic leaks, which is hard to treat through endoscopic treatment. ${ }^{131}$ The three common revisions for chronic GL are laparoscopic Roux-En-Y Esophago-Jejunostomy (LRYEJ), RYGB, and total or near total gastrectomy with esophagojejunal anastomosis. Surgical treatment remains a difficult procedure with a high percentage of leakage but is easily tolerated by a patient and facilitates the healing of the fistula. ${ }^{132}$ Among the three revisions, RYGB has the highest reoccurrence rate of leak, ${ }^{130}$ and patients who underwent gastrectomy have a relatively high risk of complications related to esophagojejunal anastomosis, nutritional deficiencies, and anemia. ${ }^{133}$ LRYEJ seems more safe and effective but with higher complications. ${ }^{134}$ LRYEJ is a well-characterized approach that anastomoses a fistula site to a small bowel loop. It is followed by distal jejunojejunostomy for the diversion of the biliary secretions. RYGB is an option for decreasing intragastric pressure and facilitates fistula healing but should be avoided in cases of severe peritonitis and hemodynamic instability. As a major surgery mode, complete gastric resection is a salvage procedure for chronic leaks with inflammation, fibrosis, dissection, and adhesions, which cannot be cured through LRYEJ or RYGB. ${ }^{135}$

GL can be prevented by gently handling tissues, reinforcing the staple line ${ }^{136}$ (or overriding sutures or buttressing materials), performing procedures by experienced surgeons, ${ }^{122,137}$ and performing proper traction on the stomach before firing ${ }^{120}$ and proper bougie $(\geq 40 \mathrm{Fr}){ }^{138}$ The use of pyloric Botulinum toxin (type A) injection during LSG can reduce the incidence of GL. ${ }^{139}$ Although the use of methylene blue test preoperatively is a conventional method in LSG, the validity of this method is still in dispute. ${ }^{140,141}$

Given that most GLs can be successfully treated with endoscopic techniques, the current case studies of revisions for treating GL are based on a small sample sizes, which have certain limitations. The management of postLSG leak is multimodal, and no accepted algorithm for the diagnosis and treatment of GL has been proposed yet. In China, $84.8 \%$ of surgeons consider Roux-en-Y bypass as a salvage procedure, ${ }^{142}$ whereas some researchers regard LRYEJ as a suitable technique after the failure of the endoscopic management of post-sleeve gastrectomy fistula. ${ }^{133,134,143}$ The determination of surgical methods depends mainly on patient disposition.

For intractable GL after LSG, proximal gastrectomy with double tract reconstruction is a safe, feasible, and minimally invasive option. ${ }^{144,145}$ However, as a novel revision surgery procedure, its applicability in clinical settings should be further examined before its long-term effects on weight and metabolism control in patients with obesity can be verified. A table about revisional surgery choices is listed in Table 1.

\section{Multiple Revisional Surgeries}

Revisional surgery is not a new type of surgery and can be considered after the failure after the first bariatric surgery. A new bariatric surgery is selected according to the initial operation method and postoperative situations. When 
Table I Complications After Laparoscopic Sleeve Gastrectomy and Revision Operations

\begin{tabular}{|c|c|c|c|}
\hline Complication & $\begin{array}{l}\text { Revisional } \\
\text { Surgery }\end{array}$ & Advantage or Indication & Shortcoming \\
\hline \multirow[t]{4}{*}{ Weight regain } & DS & $\begin{array}{l}\text { The original operation is the first part of the entire } \\
\text { operation. }^{38,39}\end{array}$ & \multirow[t]{2}{*}{$\begin{array}{l}\text { Higher incidence rates of postoperative } \\
\text { complications than reLSG. }\end{array}$} \\
\hline & RYGB & GERD & \\
\hline & reLSG & $\begin{array}{l}\text { A } 250 \mathrm{~cm} 3 \text { threshold measured through the CT scan volume } \\
\text { method. }{ }^{42-45}\end{array}$ & \\
\hline & SADI & $\begin{array}{l}\text { Longer common limb length;lower long-term complication } \\
\text { rate }^{46,47}\end{array}$ & $\begin{array}{l}\text { A worse outcome than BPD/DS when the } \\
\text { starting BMI is high }\end{array}$ \\
\hline \multirow[t]{2}{*}{ T2DM relapse } & reLSG & Same remission rates of metabolic syndrome as RYGB. ${ }^{67-69}$ & $\begin{array}{l}\text { Inferior to RYGB with regard to the control } \\
\text { of hypertension and high-density lipoprotein } \\
\text { cholesterol. }^{68}\end{array}$ \\
\hline & RYGB & $\begin{array}{l}\text { Improvement in MetS prevalence in T2DM patients with } \\
\text { obesity. }{ }^{59,64,65}\end{array}$ & \\
\hline GERD & RYGB & Absence of a correctable anatomic factor. ${ }^{98}$ & Not always effective. \\
\hline \multirow[t]{3}{*}{ Strictures } & RYGB & Creating a gastric pouch proximal to a stenosed gastric lumen & \\
\hline & Seromyotomy & Useful & $\begin{array}{l}\text { A high rate of resulting in complications, } \\
\text { such as gastric leak. }{ }^{115}\end{array}$ \\
\hline & $\begin{array}{l}\text { Median } \\
\text { gastrectomy }\end{array}$ & $\begin{array}{l}\text { Persistent stenosis within the gastric sleeve located within the } \\
\text { midbody; a low risk of leak in contrast to seromyotomy and } \\
\text { preserves the gastric sleeve option without a need to convert } \\
\text { to a gastric bypass. }{ }^{16}\end{array}$ & \\
\hline \multirow[t]{3}{*}{ Gastric Leak } & LRYEJ & $\begin{array}{l}\text { After the failure of the endoscopic management of post-sleeve } \\
\text { gastrectomy fistula. }{ }^{133,134,143}\end{array}$ & \\
\hline & RYGB & A salvage procedure. ${ }^{142}$ & \\
\hline & Gastrectomy & Intractable GL after LSG ${ }^{144,145}$ & \\
\hline
\end{tabular}

changes in a patient's physiological anatomy are considered, revisional bariatric surgery has a higher risk of existing original or new complications than initial bariatric surgery. ${ }^{146,147}$ Therefore, some patients inevitably undergo three or four bariatric surgeries.

Multiple bariatric operations require high technical skills and careful judgment on patients' conditions, as long-term outcomes regarding weight loss and comorbidity resolution are usually inferior to those of primary bariatric surgery. ${ }^{148}$ Studies on multiple bariatric surgery after LSG are few; only two statistical reports showed that RYGB is the third most effective bariatric procedure. ${ }^{149,150}$ In addition, a case report about the failure of anastomosis gastric bypass/mini-gastric bypass rescuing in patients with GERD who underwent single-anastomosis -duodeno-ileal bypass has been published. ${ }^{151}$ GERD after multiple bariatric surgeries might be caused by the repeated dissection of the angle of His and diaphragmatic crura and enlargement of natural orifices, such as the hiatal orifice. $^{152}$

Patients who underwent multiple bariatric surgeries are not a minority, and multiple operations have made their situations complicated. Thus, their subsequent therapies are difficult. In addition, criteria for performing multiple bariatric surgery have not been proposed. For multiple bariatric surgery, long-term reports are needed to prove its safety and effectiveness.

\section{LSG in East Asia}

In the literature, LSG is mostly performed in western populations. LSG is a relatively new procedure and is now commonly performed in East Asia, particularly in Japan. ${ }^{153}$ The current meta-analysis by Veeravich and his colleagues suggested that LSG is an effective procedure 
for weight reduction and offers durable response for up to 5 years among Asians with obesity. The observed surgical revision rate appears to be lower than the previously reported data from other populations. ${ }^{154}$ In a retrospective study based on prospectively collected data in South Korea, LSG and laparoscopic RYGB are effective methods that can reduce weight in the medium term and have similar surgical risks. However, most patients need revision surgery after LSG. ${ }^{155}$ A national survey in Japan showed that the mean \%TWL after LSG is $29.9 \%$, and $\% \mathrm{TWL} 20 \%$ may be the best cutoff point for diabetic remission in Japanese patients with obesity. ${ }^{156}$ According to the results of a multi-institutional survey in Japan, hypertension remission rates by procedure is in the order of laparoscopic RYGB, LSG, LSG-DJB, and laparoscopic adjustable gastric banding (LAGB) and dyslipidemia remission rates are in the order of laparoscopic RYGB, LSG-DJB, LSG, and LAGB. ${ }^{157}$ In the whole East Asia, some interesting bariatric and metabolic procedures have achieved excellent results. For example, LSG/ DJB provides patients with significant weight loss and metabolic effects. ${ }^{158}$ Another procedure is laparoscopic adjustable gastric banded plication, which may be a good alternative to LSG when a patient desires a restrictive and potentially reversible procedure. ${ }^{159,160}$

\section{Conclusion and Outlook}

Low morbidity and mortality rates associated with LSG have made it one of the most commonly used bariatric procedures worldwide and a cost-effective intervention. However, the long-term prognosis of LSG and data on revisional surgery after LSG are scarce. The main indications for revision are insufficient weight loss, GERD, strictures, GL, and persistent metabolic syndrome. ${ }^{161}$ Laparoscopic RYGB has been described as the most reasonable treatment approach and a viable option for revisional surgery. ${ }^{162}$

For the resolution of aforementioned problems, novel surgeries have been proposed. In addition to novel revisional methods already mentioned above, most promising primary bariatric surgeries include endoscopic sleeve gastroplasty (ESG) and robotic-assisted laparoscopic sleeve gastrectomy (RA-LSG). Nevertheless, many articles showed that RA-LSG is related to increased supply cost, ${ }^{163,164}$ operative time, and postoperative morbidity. ${ }^{165,166}$ ESG seems to be promising. ESG is a minimally invasive procedure that reduces the size of the gastric reservoir and appears to be well tolerated, safe, and effective ${ }^{167,168}$ with fewer adverse events and newonset GERD cases than LSG. ${ }^{169}$ Through the wide application of ESG, we can even expect bariatric surgery to become an outpatient surgery. ${ }^{170}$

\section{Abbreviations}

$\%$ EWL, percent of excess weight loss; BPD-DS, biliopancreatic diversion with duodenal switch; DJB, duodenojejunal bypass; DPP-4, dipeptidyl peptidase-4; DS, duodenal switch; EGJ, esophagogastric junction; ESG, endoscopic sleeve gastroplasty; GERD, gastroesophageal reflux disease; GL, Gastric leak; GS, gastric stenosis; HH, hiatal hernia; HHR, hiatal hernia repair; LAGB, laparoscopic adjustable gastric banding; LES, lower esophageal sphincter; LRYEJ, Roux-En-Y Esophago-Jejunostomy; LSG, laparoscopic sleeve gastrectomy; LTC, ligamentum teres cardiopexy; OAGB, One-anastomosis gastric bypass; RA-LSG, robotic-assisted laparoscopic sleeve gastrectomy; ReSG, revisional sleeve gastrectomy; RYGB, Roux-en-Y gastric bypass; SADI, singleanastomosis duodeno-ileal bypass; SG, sleeve gastrectomy; WR, weight regain, regaining weight to achieve a $\mathrm{BMI}>35$.

\section{Acknowledgments}

Thanks to the colleagues from library for their help during the process of literature review.

\section{Funding}

No funding was received for writing this study.

\section{Disclosure}

All authors declare that they have no conflicts of interest for this work.

\section{References}

1. Mohammed MS, Sendra S, Lloret J, Bosch I. Systems and WBANs for controlling obesity. J Healthc Eng. 2018;2018:1564748. doi:10.1155/ 2018/1564748

2. Switzer NJ, Karmali S, Gill RS, Sherman V. Revisional bariatric surgery. Surg Clin North Am. 2016;96(4):827-842. doi:10.1016/j. suc.2016.03.004

3. Angrisani L, Santonicola A, Iovino P, et al. IFSO worldwide survey 2016: primary, endoluminal, and revisional procedures. Obes Surg. 2018;28(12):3783-3794. doi:10.1007/s11695-018-3450-2

4. Wolfe BM, Kvach E, Eckel RH. Treatment of obesity: weight loss and bariatric surgery. Circ Res. 2016;118(11):1844-1855. doi:10.1161/ CIRCRESAHA.116.307591

5. Mann JP, Jakes AD, Hayden JD, Barth JH. Systematic review of definitions of failure in revisional bariatric surgery. Obes Surg. 2015;25(3):571-574. doi:10.1007/s11695-014-1541-2 
6. Brethauer SA, Kothari S, Sudan R, et al. Systematic review on reoperative bariatric surgery: American Society for Metabolic and Bariatric Surgery Revision Task Force. Surg Obes Relat Dis. 2014;10(5):952-972. doi:10.1016/j.soard.2014.02.014

7. Nedelcu M, Khwaja HA, Rogula TG. Weight regain after bariatric surgery - how should it be defined? Surg Obesity Related Dis. 2016;12(5):1129-1130. doi:10.1016/j.soard.2016.04.028

8. Bakr AA, Fahmy MH, Elward AS, Balamoun HA, Ibrahim MY, Eldahdoh RM. Analysis of medium-term weight regain 5 years after laparoscopic sleeve gastrectomy. Obes Surg. 2019;29 (11):3508-3513. doi:10.1007/s11695-019-04009-w

9. Velapati SR, Shah M, Kuchkuntla AR, et al. Weight regain after bariatric surgery: prevalence, etiology, and treatment. Curr Nutr Rep. 2018;7(4):329-334. doi:10.1007/s13668-018-0243-0

10. Rosenthal RJ, Diaz AA, Arvidsson D, et al. International sleeve gastrectomy expert panel consensus statement: best practice guidelines based on experience of $>12,000$ cases. Surg Obesity Related Dis. 2012;8(1):8-19. doi:10.1016/j.soard.2011.10.019

11. Abd Ellatif ME, Abdallah E, Askar W, et al. Long term predictors of success after laparoscopic sleeve gastrectomy. Int J Surg. 2014;12(5):504-508. doi:10.1016/j.ijsu.2014.02.008

12. Balla A, Quaresima S, Leonetti F, et al. Laparoscopic sleeve gastrectomy changes in the last decade: differences in morbidity and weight loss. J Soc Laparoendosc Surg. 2017;27 (11):1165-1171. doi:10.1089/lap.2017.0059

13. Yu Y, Klem ML, Kalarchian MA, Ji M, Burke LE. Predictors of weight regain after sleeve gastrectomy: an integrative review. Surg Obes Relat Dis. 2019;15(6):995-1005. doi:10.1016/j. soard.2019.02.009

14. Lauti M, Kularatna M, Hill AG, MacCormick AD. Weight regain following sleeve gastrectomy - a systematic review. Obes Surg. 2016;26(6):1326-1334. doi:10.1007/s11695-016-2152-x

15. Fink JM, Hoffmann N, Kuesters S, et al. Banding the sleeve improves weight loss in midterm follow-up. Obes Surg. 2017;27 (4):1098-1103. doi:10.1007/s11695-017-2610-0

16. Lemmens L, Van Den Bossche J, Zaveri H, Surve A. Banded sleeve gastrectomy: better long-term results? A long-term cohort study until 5 years follow-up in obese and superobese patients. Obes Surg. 2018;28(9):2687-2695. doi:10.1007/s11695-018-3248-2

17. Weiner RA, Weiner S, Pomhoff I, Jacobi C, Makarewicz W, Weigand G. Laparoscopic sleeve gastrectomy - influence of sleeve size and resected gastric volume. Obes Surg. 2007;17 (10):1297. doi:10.1007/s11695-007-9232-x

18. Abdallah E, El Nakeeb A, Yousef T, et al. Impact of extent of antral resection on surgical outcomes of sleeve gastrectomy for morbid obesity (a prospective randomized study). Obes Surg. 2014;24(10):1587-1594. doi:10.1007/s11695-014-1242-x

19. Obeidat F, Shanti H, Mismar A, Albsoul N, Al-Qudah M. The magnitude of antral resection in laparoscopic sleeve gastrectomy and its relationship to excess weight loss. Obes Surg. 2015;25 (10):1928-1932. doi:10.1007/s11695-015-1642-6

20. Disse E, Pasquer A, Pelascini E, et al. Dilatation of sleeve gastrectomy: myth or reality? Obes Surg. 2017;27(1):30-37. doi:10.1007/s11695-016-2261-6

21. Pizza F, D'Antonio D, Lucido FS, et al. Does antrum size matter in sleeve gastrectomy? A prospective randomized study. Surg Endosc. 2020.

22. Garay M, Balagué C, Rodríguez-Otero $\mathrm{C}$, et al. Influence of antrum size on gastric emptying and weight-loss outcomes after laparoscopic sleeve gastrectomy (preliminary analysis of a randomized trial). Surg Endosc. 2018;32(6):2739-2745. doi:10.1007/s00464-017-5972-4

23. Chopra A, Chao E, Etkin Y, Merklinger L, Lieb J, Delany H. Laparoscopic sleeve gastrectomy for obesity: can it be considered a definitive procedure? Surg Endosc. 2012;26(3):831-837. doi:10.1007/s00464-011-1960-2
24. Binda A, Jaworski P, Kudlicka E, Ciesielski A, Cabaj H, Tarnowski W. The impact of selected factors on parameters of weight loss after sleeve gastrectomy. Wideochir Inne Tech Maloinwazyjne. 2016;11(4):288-294. doi:10.5114/wiitm. 2016.64999

25. Contreras JE, Santander C, Court I, Bravo J. Correlation between age and weight loss after bariatric surgery. Obes Surg. 2013;23 (8):1286-1289. doi:10.1007/s11695-013-0905-3

26. Eisenberg D, Bellatorre A, Bellatorre N. Sleeve gastrectomy as a stand-alone bariatric operation for severe, morbid, and super obesity. J Soc Laparoendosc Surg. 2013;17(1):63-67. doi:10.4293/108680812X13517013317077

27. White MA, Kalarchian MA, Masheb RM, Marcus MD, Grilo CM. Loss of control over eating predicts outcomes in bariatric surgery patients: a prospective, 24-month follow-up study. J Clin Psychiatry. 2010;71(2):175-184. doi:10.4088/ JCP.08m04328blu

28. Goldschmidt AB, Khoury J, Jenkins TM, et al. Adolescent loss-of-control eating and weight loss maintenance after bariatric surgery. Pediatrics. 2018;141(1):e20171659. doi:10.1542/ peds.2017-1659

29. Ivezaj V, Kessler EE, Lydecker JA, Barnes RD, White MA, Grilo CM. Loss-of-control eating following sleeve gastrectomy surgery. Surg Obesity Related Dis. 2017;13(3):392-398. doi:10.1016/j.soard.2016.09.028

30. Rottenstreich A, Shufanieh J, Kleinstern G, Goldenshluger A, Elchalal U, Elazary R. The long-term effect of pregnancy on weight loss after sleeve gastrectomy. Surg Obesity Related Dis. 2018;14(10):1594-1599. doi:10.1016/j.soard.2018.07.008

31. Quyên Pham T, Pigeyre M, Caiazzo R, Verkindt H, Deruelle P, Pattou F. Does pregnancy influence long-term results of bariatric surgery? Surg Obesity Related Dis. 2015;11(5):1134-1139. doi:10.1016/j.soard.2015.03.015

32. Froylich D, Corcelles R, Daigle CR, Kirwan JP, Brethauer SA, Schauer PR. The effect of pregnancy before and/or after bariatric surgery on weight loss. Surg Obesity Related Dis. 2016;12 (3):596-599. doi:10.1016/j.soard.2015.09.005

33. Bohdjalian A, Langer FB, Shakeri-Leidenmühler S, et al. Sleeve gastrectomy as sole and definitive bariatric procedure: 5-year results for weight loss and ghrelin. Obes Surg. 2010;20 (5):535-540. doi:10.1007/s11695-009-0066-6

34. Demerdash HM, Sabry AA, Arida EA. Role of serotonin hormone in weight regain after sleeve gastrectomy. Scand J Clin Lab Invest. 2018;78(1-2):68-73. doi:10.1080/00365513.2017. 1413714

35. Alvarez V, Carrasco F, Cuevas A, et al. Mechanisms of long-term weight regain in patients undergoing sleeve gastrectomy. Nutrition (Burbank, Los Angeles County, Calif). 2016;32 (3):303-308. doi:10.1016/j.nut.2015.08.023

36. Lauti M, Stevenson S, Hill AG, MacCormick AD. Patient perspectives about follow-up care and weight regain following sleeve gastrectomy. Obes Surg. 2016;26(11):2724-2731. doi:10.1007/s11695-016-2178-0

37. Mingrone G. Treatment of persistent or recurrent type 2 diabetes after metabolic surgery. Lancet Diabetes Endocrinol. 2019;7 (7):504-505. doi:10.1016/S2213-8587(19)30195-0

38. Marceau P, Biron S, Bourque RA, Potvin M, Hould FS, Simard S Biliopancreatic diversion with a new type of gastrectomy. Obes Surg. 1993;3(1):29-35. doi:10.1381/096089293765559728

39. Hess DS, Hess DW. Biliopancreatic diversion with a duodenal switch. Obes Surg. 1998;8(3):267-282. doi:10.1381/ 096089298765554476

40. Saliba C, El Rayes J, Diab S, Nicolas G, Wakim R. Weight regain after sleeve gastrectomy: a look at the benefits of re-sleeve. Cureus. 2018;10(10):e3450. 
41. Iannelli A, Schneck AS, Noel P, Ben Amor I, Krawczykowski D, Gugenheim J. Re-sleeve gastrectomy for failed laparoscopic sleeve gastrectomy: a feasibility study. Obes Surg. 2011;21 (7):832-835. doi:10.1007/s11695-010-0290-0

42. Braghetto I, Davanzo C, Korn O, et al. Scintigraphic evaluation of gastric emptying in obese patients submitted to sleeve gastrectomy compared to normal subjects. Obes Surg. 2009;19 (11):1515-1521. doi:10.1007/s11695-009-9954-Z

43. Deguines JB, Verhaeghe P, Yzet T, Robert B, Cosse C, Regimbeau JM. Is the residual gastric volume after laparoscopic sleeve gastrectomy an objective criterion for adapting the treatment strategy after failure? Surg Obesity Related Dis. 2013;9 (5):660-666. doi:10.1016/j.soard.2012.11.010

44. Noel P, Nedelcu M, Nocca D, et al. Revised sleeve gastrectomy: another option for weight loss failure after sleeve gastrectomy. Surg Endosc. 2014;28(4):1096-1102. doi:10.1007/s00464-0133277-9

45. Rebibo L, Fuks D, Verhaeghe P, Deguines JB, Dhahri A, Regimbeau JM. Repeat sleeve gastrectomy compared with primary sleeve gastrectomy: a single-center, matched case study. Obes Surg. 2012;22(12):1909-1915. doi:10.1007/s11695-0120779-9

46. Lee Y, Ellenbogen Y, Doumouras AG, Gmora S, Anvari M, Hong D. Single- or double-anastomosis duodenal switch versus Roux-en-Y gastric bypass as a revisional procedure for sleeve gastrectomy: a systematic review and meta-analysis. Surg Obesity Related Dis. 2019;15(4):556-566. doi:10.1016/j.soard.2019.01.022

47. Sánchez-Pernaute A, Rubio M, Pérez N, Marcuello C, Torres A, Pérez-Aguirre E. Single-anastomosis duodenoileal bypass as a revisional or second-step operation after sleeve gastrectomy. Surg Obesity Related Dis. 2020;16(10):1491-1496. doi:10.1016/ j.soard.2020.05.022

48. Nedelcu M, Noel P, Iannelli A, Gagner M. Revised sleeve gastrectomy (re-sleeve). Surg Obesity Related Dis. 2015;11 (6):1282-1288. doi:10.1016/j.soard.2015.02.009

49. Baltasar A, Serra C, Pérez N, Bou R, Bengochea M. Re-sleeve gastrectomy. Obes Surg. 2006;16(11):1535-1538. doi:10.1381/ 096089206778869924

50. Noel P, Nedelcu A, Eddbali I, Gagner M, Danan M, Nedelcu M. Five-year results after resleeve gastrectomy. Surg Obesity Related Dis. 2020;16(9):1186-1191. doi:10.1016/j.soard.2020.04.021

51. Gautier T, Sarcher T, Contival N, Le Roux Y, Alves A. Indications and mid-term results of conversion from sleeve gastrectomy to Roux-en-Y gastric bypass. Obes Surg. 2013;23 (2):212-215. doi:10.1007/s11695-012-0782-1

52. Aminian A. Sleeve gastrectomy: metabolic surgical procedure of choice? Trends Endocrinol Metab. 2018;29(8):531-534. doi:10.1016/j.tem.2018.04.011

53. Gill RS, Birch DW, Shi X, Sharma AM, Karmali S. Sleeve gastrectomy and type 2 diabetes mellitus: a systematic review. Surg Obesity Related Dis. 2010;6(6):707-713. doi:10.1016/j. soard.2010.07.011

54. Capoccia D, Coccia F, Guarisco G, et al. Long-term metabolic effects of laparoscopic sleeve gastrectomy. Obes Surg. 2018;28 (8):2289-2296. doi:10.1007/s11695-018-3153-8

55. Schauer PR, Kashyap SR, Wolski K, et al. Bariatric surgery versus intensive medical therapy in obese patients with diabetes. $N$ Engl $J$ Med. 2012;366(17):1567-1576. doi:10.1056/ NEJMoa1200225

56. Panunzi S, Carlsson L, De Gaetano A, et al. Determinants of diabetes remission and glycemic control after bariatric surgery. Diabetes Care. 2016;39(1):166. doi:10.2337/dc15-0575

57. Aminian A, Brethauer SA, Andalib A, et al. Can sleeve gastrectomy "cure" diabetes? Long-term metabolic effects of sleeve gastrectomy in patients with type 2 diabetes. Ann Surg. 2016;264 (4):674-681. doi:10.1097/SLA.0000000000001857
58. Lylloff L, Bathum L, Madsbad S, Grundtvig JLG, NordgaardLassen I, Fenger M. S100A8/A9 (calprotectin), interleukin-6, and C-reactive protein in obesity and diabetes before and after Roux-en-Y gastric bypass surgery. Obes Facts. 2017;10 (4):386-395. doi:10.1159/000478097

59. Yu H, Zhang L, Bao Y, et al. Metabolic syndrome after Roux-en$\mathrm{Y}$ gastric bypass surgery in Chinese obese patients with type 2 diabetes. Obes Surg. 2016;26(9):2190-2197. doi:10.1007/s11695016-2074-7

60. Schauer PR, Bhatt DL, Kirwan JP, et al. Bariatric surgery versus intensive medical therapy for diabetes -5 -year outcomes. $N$ Engl J Med. 2017;376(7):641-651. doi:10.1056/ NEJMoa1600869

61. Laferrère $B$, Heshka $S$, Wang $\mathrm{K}$, et al. Incretin levels and effect are markedly enhanced 1 month after Roux-en-Y gastric bypass surgery in obese patients with type 2 diabetes. Diabetes Care. 2007;30(7):1709-1716. doi:10.2337/dc06-1549

62. Jørgensen NB, Dirksen C, Bojsen-Møller KN, et al. Exaggerated glucagon-like peptide 1 response is important for improved $\beta$-cell function and glucose tolerance after Roux-en-Y gastric bypass in patients with type 2 diabetes. Diabetes. 2013;62(9):3044-3052. doi: $10.2337 / \mathrm{db} 13-0022$

63. Deacon CF. Circulation and degradation of GIP and GLP-1. Hormone Metabol Res. 2004;36(11-12):761-765. doi:10.1055/ s-2004-826160

64. Guerreiro V, Neves JS, Salazar D, et al. Long-term weight loss and metabolic syndrome remission after bariatric surgery: the effect of sex, age, metabolic parameters and surgical technique a 4-year follow-up study. Obes Facts. 2019;12(6):639-652. doi: $10.1159 / 000503753$

65. Batsis JA, Romero-Corral A, Collazo-Clavell ML, Sarr MG, Somers VK, Lopez-Jimenez F. Effect of bariatric surgery on the metabolic syndrome: a population-based, long-term controlled study. Mayo Clin Proc. 2008;83(8):897-907. doi:10.1016/ S0025-6196(11)60766-0

66. Aleassa EM, Hassan M, Hayes K, Brethauer SA, Schauer PR, Aminian A. Effect of revisional bariatric surgery on type 2 diabetes mellitus. Surg Endosc. 2019;33(8):2642-2648. doi:10.1007/s00464-018-6541-1

67. Nassour I, Almandoz JP, Adams-Huet B, Kukreja S, Puzziferri N. Metabolic syndrome remission after Roux-en-Y gastric bypass or sleeve gastrectomy. Diabetes Metabol Syndr Obesity. 2017;10:393-402. doi:10.2147/DMSO.S142731

68. Du X, Fu XH, Peng BQ, Luo R, Hu JK, Cheng Z. Resolution of metabolic syndrome and related metabolic disorders after bariatric surgery: comparison of sleeve gastrectomy and gastric bypass. Surg Obesity Related Dis. 2018;14(9):1348-1356. doi:10.1016/j.soard.2018.05.016

69. Osland E, Yunus RM, Khan S, Memon B, Memon MA. Diabetes improvement and resolution following laparoscopic vertical sleeve gastrectomy (LVSG) versus laparoscopic Roux-en-Y gastric bypass (LRYGB) procedures: a systematic review of randomized controlled trials. Surg Endosc. 2017;31(4):1952-1963. doi:10.1007/s00464-016-5202-5

70. Lee WJ, Chong K, Lee YC, et al. Effects of obesity surgery on type 2 diabetes mellitus Asian patients. World J Surg. 2009;33 (9):1895-1903. doi:10.1007/s00268-009-0115-2

71. Aminian A, Brethauer SA, Andalib A, et al. Individualized metabolic surgery score: procedure selection based on diabetes severity. Ann Surg. 2017;266(4):650-657. doi:10.1097/ SLA.0000000000002407

72. Chang D-M, Lee W-J, Chen J-C, Ser K-H, Tsai P-L, Lee Y-C. Thirteen-year experience of laparoscopic sleeve gastrectomy: surgical risk, weight loss, and revision procedures. Obes Surg. 2018;28(10):2991-2997. doi:10.1007/s11695-018-3344-3 
73. Lee WJ, Ser KH, Chong K, et al. Laparoscopic sleeve gastrectomy for diabetes treatment in nonmorbidly obese patients: efficacy and change of insulin secretion. Surgery. 2010;147 (5):664-669. doi:10.1016/j.surg.2009.10.059

74. Lee WJ, Almulaifi A, Tsou JJ, Ser KH, Lee YC, Chen SC. Laparoscopic sleeve gastrectomy for type 2 diabetes mellitus: predicting the success by ABCD score. Surg Obesity Related Dis. 2015;11(5):991-996.

75. Gu L, Chen B, Du N, et al. Relationship between bariatric surgery and gastroesophageal reflux disease: a systematic review and meta-analysis. Obes Surg. 2019;29(12):4105-4113. doi:10.1007/ s11695-019-04218-3

76. Rebecchi F, Allaix ME, Patti MG, Schlottmann F, Morino M. Gastroesophageal reflux disease and morbid obesity: to sleeve or not to sleeve? World J Gastroenterol. 2017;23(13):2269-2275. doi:10.3748/wjg.v23.i13.2269

77. Naik RD, Choksi YA, Vaezi MF. Consequences of bariatric surgery on oesophageal function in health and disease. Nat Rev Gastroenterol Hepatol. 2016;13(2):111-119. doi:10.1038/ nrgastro.2015.202

78. Bou Daher H, Sharara AI. Gastroesophageal reflux disease, obesity and laparoscopic sleeve gastrectomy: the burning questions. World J Gastroenterol. 2019;25(33):4805-4813. doi:10.3748/wjg. v25.i33.4805

79. Csendes A, Orellana O, Martínez G, Burgos AM, Figueroa M, Lanzarini E. Clinical, endoscopic, and histologic findings at the distal esophagus and stomach before and late (10.5 years) after laparoscopic sleeve gastrectomy: results of a prospective study with 93\% follow-up. Obes Surg. 2019;29(12):3809-3817. doi:10.1007/s11695-019-04054-5

80. Khidir N, Angrisani L, Al-Qahtani J, Abayazeed S, Bashah M. Initial experience of endoscopic radiofrequency waves delivery to the lower esophageal sphincter (stretta procedure) on symptomatic gastroesophageal reflux disease post-sleeve gastrectomy. Obes Surg. 2018;28(10):3125-3130. doi:10.1007/s11695-018-3333-6

81. Gyawali CP, Kahrilas PJ, Savarino E, et al. Modern diagnosis of GERD: the lyon consensus. Gut. 2018;67(7):1351-1362. doi:10.1136/gutjnl-2017-314722

82. Thereaux J, Barsamian $\mathrm{C}$, Bretault $\mathrm{M}$, et al. $\mathrm{pH}$ monitoring of gastro-oesophageal reflux before and after laparoscopic sleeve gastrectomy. $B r \quad J$ Surg. 2016;103(4):399-406. doi:10.1002/ bjs. 10089

83. Georgia D, Stamatina T, Maria N, et al. 24-h multichannel intraluminal impedance PH-metry 1 year after laparoscopic sleeve gastrectomy: an objective assessment of gastroesophageal reflux disease. Obes Surg. 2017;27(3):749-753. doi:10.1007/s11695016-2359-x

84. Di Lorenzo N, Antoniou SA, Batterham RL, et al. Clinical practice guidelines of the European Association for Endoscopic Surgery (EAES) on bariatric surgery: update 2020 endorsed by IFSO-EC, EASO and ESPCOP. Surg Endosc. 2020;34 (6):2332-2358. doi:10.1007/s00464-020-07555-y

85. Zhang C, Liu D, Li F, et al. Systematic review and meta-analysis of laparoscopic mesh versus suture repair of hiatus hernia: objective and subjective outcomes. Surg Endosc. 2017;31 (12):4913-4922. doi:10.1007/s00464-017-5586-x

86. Samakar K, McKenzie TJ, Tavakkoli A, Vernon AH, Robinson MK, Shikora SA. The effect of laparoscopic sleeve gastrectomy with concomitant hiatal hernia repair on gastroesophageal reflux disease in the morbidly obese. Obes Surg. 2016;26 (1):61-66. doi:10.1007/s11695-015-1737-0

87. Dakour Aridi H, Asali M, Fouani T, Alami RS, Safadi BY Gastroesophageal reflux disease after laparoscopic sleeve gastrectomy with concomitant hiatal hernia repair: an unresolved question. Obes Surg. 2017;27(11):2898-2904. doi:10.1007/ s11695-017-2702-x
88. Santonicola A, Angrisani L, Cutolo P, Formisano G, Iovino P. The effect of laparoscopic sleeve gastrectomy with or without hiatal hernia repair on gastroesophageal reflux disease in obese patients. Surg Obes Relat Dis. 2014;10(2):250-255. doi:10.1016/j. soard.2013.09.006

89. Salama A, Saafan T, El Ansari W, Karam M, Bashah M. Is routine preoperative esophagogastroduodenoscopy screening necessary prior to laparoscopic sleeve gastrectomy? Review of 1555 cases and comparison with current literature. Obes Surg. 2018;28(1):52-60. doi:10.1007/s11695-017-2813-4

90. El Ansari W, El-Menyar A, Sathian B, Al-Thani H, Al-Kuwari M, Al-Ansari A. Is routine preoperative esophagogastroduodenoscopy prior to bariatric surgery mandatory? Systematic review and meta-analysis of 10,685 patients. Obes Surg. 2020;30 (8):3073-3083. doi:10.1007/s11695-020-04672-4

91. Assalia A, Gagner M, Nedelcu M, Ramos AC, Nocca D. Gastroesophageal reflux and laparoscopic sleeve gastrectomy: results of the first international consensus conference. Obes Surg. 2020;30:3695-3705. doi:10.1007/s11695-020-04749-0

92. Stefanidis D, Hope WW, Kohn GP, Reardon PR, Richardson WS, Fanelli RD. Guidelines for surgical treatment of gastroesophageal reflux disease. Surg Endosc. 2010;24(11):2647-2669.

93. Hawasli A, Bush A, Hare B, Meguid A, Thatimatla N, Szpunar S Laparoscopic management of severe reflux after sleeve gastrectomy, in selected patients, without conversion to Roux-en-Y gastric bypass. J Laparoendosc Adv Surg Tech A. 2015;25 (8):631-635. doi:10.1089/lap.2015.0079

94. Frazzoni M, Piccoli M, Conigliaro R, Frazzoni L, Melotti G. Laparoscopic fundoplication for gastroesophageal reflux disease. World J Gastroenterol. 2014;20(39):14272-14279. doi:10.3748/ wjg.v20.139.14272

95. Kichler K, Rosenthal RJ, DeMaria E, Higa K. Reoperative surgery for nonresponders and complicated sleeve gastrectomy operations in patients with severe obesity. An international expert panel consensus statement to define best practice guidelines. Surg Obesity Related Dis. 2019;15(2):173-186. doi:10.1016/j. soard.2018.11.006

96. Page PL, Martin D, Taylor C, et al. Does hiatal repair affect gastroesophageal reflux symptoms in patients undergoing laparoscopic sleeve gastrectomy? Surg Endosc. 2018;32(5):2373-2380. doi:10.1007/s00464-017-5935-9

97. Ostruszka P, Ihnát P, Tulinský L, Vávra P. An alternative method of surgical treatment in refractory GERD following laparoscopic sleeve gastrectomy. Rozhl Chir. 2019;98(5):214-218.

98. Iannelli A, Debs T, Martini F, Benichou B, Ben Amor I, Gugenheim J. Laparoscopic conversion of sleeve gastrectomy to Roux-en-Y gastric bypass: indications and preliminary results. Surg Obesity Related Dis. 2016;12(8):1533-1538. doi:10.1016/j. soard.2016.04.008

99. Guan B, Chong TH, Peng J, Chen Y, Wang C, Yang J. Mid-longterm revisional surgery after sleeve gastrectomy: a systematic review and meta-analysis. Obes Surg. 2019;29(6):1965-1975. doi:10.1007/s11695-019-03842-3

100. Madalosso CA, Gurski RR, Callegari-Jacques SM, Navarini D, Mazzini G, Pereira Mda S. The impact of gastric bypass on gastroesophageal reflux disease in morbidly obese patients. Ann Surg. 2016;263(1):110-116. doi:10.1097/SLA.0000000000001139

101. Tolone S, Savarino E, Yates RB. The impact of bariatric surgery on esophageal function. Ann N Y Acad Sci. 2016;1381(1):98-103. doi:10.1111/nyas. 13107

102. Vilallonga R, Sanchez-Cordero S, Alberti P, Blanco-Colino R. Ligamentum teres cardiopexy as a late alternative for gastroesophageal reflux disease in a patient with previous reversal of gastric bypass to sleeve gastrectomy and hiatal hernia repair. Obes Surg. 2019;29(11):3765-3768. doi:10.1007/s11695-01903990-6 
103. Gálvez-Valdovinos R, Cruz-Vigo JL, Marín-Santillán E, FunesRodríguez JF, López-Ambriz G, Domínguez-Carrillo LG. Cardiopexy with ligamentum teres in patients with hiatal hernia and previous sleeve gastrectomy: an alternative treatment for gastroesophageal reflux disease. Obes Surg. 2015;25 (8):1539-1543. doi:10.1007/s11695-015-1740-5

104. Carandina S, Soprani A, Montana L, et al. Conversion of sleeve gastrectomy to Roux-en-Y gastric bypass in patients with gastroesophageal reflux disease: results of a multicenter study. Surg Obesity Related Dis. 2020;16(6):732-737. doi:10.1016/j. soard.2020.02.009

105. Merz AE, Blackstone RB, Gagner M, et al. Duodenal switch in revisional bariatric surgery: conclusions from an expert consensus panel. Surg Obesity Related Dis. 2019;15(6):894-899. doi:10.1016/j.soard.2019.03.009

106. Homan J, Betzel B, Aarts EO, van Laarhoven KJ, Janssen IM, Berends FJ. Secondary surgery after sleeve gastrectomy: Roux-en-Y gastric bypass or biliopancreatic diversion with duodenal switch. Surg Obes Relat Dis. 2015;11(4):771-777. doi:10.1016/j.soard.2014.09.029

107. Parmar CD, Mahawar KK, Boyle M, Schroeder N, Balupuri S, Small PK. Conversion of sleeve gastrectomy to Roux-en-Y gastric bypass is effective for gastro-oesophageal reflux disease but not for further weight loss. Obes Surg. 2017;27(7):1651-1658. doi:10.1007/s11695-017-2542-8

108. Amiki M, Seki Y, Kasama K, et al. Revisional bariatric surgery for insufficient weight loss and gastroesophageal reflux disease: our 12-year experience. Obes Surg. 2020;30(5):1671-1678. doi:10.1007/s11695-019-04374-6

109. Rebibo L, Hakim S, Dhahri A, Yzet T, Delcenserie R, Regimbeau J-M. Gastric stenosis after laparoscopic sleeve gastrectomy: diagnosis and management. Obes Surg. 2016;26 (5):995-1001. doi:10.1007/s11695-015-1883-4

110. Burgos AM, Csendes A, Braghetto I. Gastric stenosis after laparoscopic sleeve gastrectomy in morbidly obese patients. Obes Surg. 2013;23(9):1481-1486. doi:10.1007/s11695-013-0963-6

111. Lalor PF, Hopkins LJ, Reynolds GM. Complications after laparoscopic sleeve gastrectomy. Am J Pathol. 2014;184:1550-7289. doi:10.1016/j.ajpath.2014.01.034

112. Chang PC, Tai CM, Hsin MC, Hung CM, Huang IY, Huang CK. Surgical standardization to prevent gastric stenosis after laparoscopic sleeve gastrectomy: a case series. Surg Obesity Related Dis. 2017;13(3):385-390. doi:10.1016/j.soard.2016.09.014

113. Nedelcu M, Manos T, Cotirlet A, Noel P, Gagner M. Outcome of leaks after sleeve gastrectomy based on a new algorithm addressing leak size and gastric stenosis. Obes Surg. 2015;25 (3):559-563. doi:10.1007/s11695-014-1561-y

114. Parikh A, Alley JB, Peterson RM, et al. Management options for symptomatic stenosis after laparoscopic vertical sleeve gastrectomy in the morbidly obese. Surg Endosc. 2012;26(3):738-746. doi:10.1007/s00464-011-1945-1

115. Vilallonga R, Himpens J, van de Vrande S. Laparoscopic management of persistent strictures after laparoscopic sleeve gastrectomy. Obes Surg. 2013;23(10):1655-1661. doi:10.1007/s11695-0130993-0

116. Kalaiselvan R, Ammori BJ. Laparoscopic median gastrectomy for stenosis following sleeve gastrectomy. Surg Obesity Related Dis. 2015;11(2):474-477. doi:10.1016/j.soard.2014.06.021

117. Jurowich C, Thalheimer A, Seyfried F, et al. Gastric leakage after sleeve gastrectomy-clinical presentation and therapeutic options. Langenbecks Arch Surg. 2011;396(7):981-987. doi:10.1007/ s00423-011-0800-0

118. Bruce J, Krukowski ZH, Al-Khairy G, Russell EM, Park KG. Systematic review of the definition and measurement of anastomotic leak after gastrointestinal surgery. Br J Surg. 2001;88 (9):1157-1168. doi:10.1046/j.0007-1323.2001.01829.x
119. Gagner M, Kemmeter P. Comparison of laparoscopic sleeve gastrectomy leak rates in five staple-line reinforcement options: a systematic review. Surg Endosc. 2020;34(1):396-407. doi:10.1007/s00464-019-06782-2

120. Iossa A, Abdelgawad M, Watkins BM, Silecchia G. Leaks after laparoscopic sleeve gastrectomy: overview of pathogenesis and risk factors. Langenbecks Arch Surg. 2016;401(6):757-766. doi:10.1007/s00423-016-1464-6

121. Griffith PS, Birch DW, Sharma AM, Karmali S. Managing complications associated with laparoscopic Roux-en-Y gastric bypass for morbid obesity. Can J Surg. 2012;55(5):329-336. doi:10.1503/cjs.002011

122. Cesana G, Cioffi S, Giorgi R, et al. Proximal leakage after laparoscopic sleeve gastrectomy: an analysis of preoperative and operative predictors on 1738 consecutive procedures. Obes Surg. 2018;28(3):627-635. doi:10.1007/s11695-017-2907-z

123. Burgos AM, Braghetto I, Csendes A, et al. Gastric leak after laparoscopic-sleeve gastrectomy for obesity. Obes Surg. 2009;19 (12):1672-1677. doi:10.1007/s11695-009-9884-9

124. Leeds SG, Burdick JS. Management of gastric leaks after sleeve gastrectomy with endoluminal vacuum (E-Vac) therapy. Surg Obes Relat Dis. 2016;12(7):1278-1285. doi:10.1016/j. soard.2016.01.017

125. Shoar S, Poliakin L, Khorgami Z, et al. Efficacy and safety of the Over-the-Scope Clip (OTSC) system in the management of leak and fistula after laparoscopic sleeve gastrectomy: a systematic review. Obes Surg. 2017;27(9):2410-2418. doi:10.1007/s11695017-2651-4

126. Zachariah PJ, Lee W-J, Ser K-H, Chen J-C, Tsou -J-J. LaparoEndoscopic Gastrostomy (LEG) decompression: a novel one-time method of management of gastric leaks following sleeve gastrectomy. Obes Surg. 2015;25(11):2213-2218. doi:10.1007/ s11695-015-1856-7

127. Dammaro C, Lainas P, Dumont JL, Tranchart H, Donatelli G, Dagher I. Endoscopic internal drainage coupled to prompt external drainage mobilization is an effective approach for the treatment of complicated cases of sleeve gastrectomy. Obes Surg. 2019;29(9):2929-2935. doi:10.1007/s11695-019-03933-1

128. Currò G, Piscitelli G, Lazzara C, et al. Laparoscopic sleeve gastrectomy for morbid obesity: role of intraluminal and intraperitoneal postoperative drainage. G Chir. 2017;38(4):181-184. doi:10.11138/gchir/2017.38.4.181

129. Al-Kurd A, Grinbaum R, Abubeih A, et al. Not all leaks are created equal: a comparison between leaks after sleeve gastrectomy and Roux-En-Y gastric bypass. Obes Surg. 2018;28 (12):3775-3782. doi:10.1007/s11695-018-3409-3

130. Nedelcu M, Danan M, Noel P, Gagner M, Nedelcu A, Carandina S. Surgical management for chronic leak following sleeve gastrectomy: review of literature. Surg Obes Relat Dis. 2019;15(10):1844-1849. doi:10.1016/j.soard.2019.03.015

131. Abraham A, Rizvon K, Singh J, et al. Successful management of a gastric sleeve leak with an endoscopic stent. Case Rep Gastrointest Med. 2012;2012:205979. doi:10.1155/2012/205979

132. Nedelcu AM, Skalli M, Deneve E, Fabre JM, Nocca D. Surgical management of chronic fistula after sleeve gastrectomy. Surg Obes Relat Dis. 2013;9(6):879-884. doi:10.1016/j. soard.2013.02.010

133. Amor IB, Debs T, Dalmonte G, et al. Laparoscopic Roux-En-Y fistulo-jejunostomy, a preferred technique after failure of endoscopic and radiologic management of fistula post sleeve gastrectomy. Obes Surg. 2019;29(2):749-750. doi:10.1007/ s11695-018-03644-z

134. Mahmoud M, Maasher A, Al Hadad M, Salim E, Nimeri AA. Laparoscopic Roux En Y esophago-jejunostomy for chronic leak/ fistula after laparoscopic sleeve gastrectomy. Obes Surg. 2016;26 (3):679-682. doi:10.1007/s11695-015-2018-7 
135. Bruzzi M, Douard R, Voron T, Berger A, Zinzindohoue F, Chevallier JM. Open total gastrectomy with Roux-en-Y reconstruction for a chronic fistula after sleeve gastrectomy. Surg Obes Relat Dis. 2016;12(10):1803-1808. doi:10.1016/j.soard.2016.03.013

136. Choi YY, Bae J, Hur KY, Choi D, Kim YJ. Reinforcing the staple line during laparoscopic sleeve gastrectomy: does it have advantages? A meta-analysis. Obes Surg. 2012;22(8):1206-1213. doi:10.1007/s11695-012-0674-4

137. Hany M, Ibrahim M. Comparison between stable line reinforcement by barbed suture and non-reinforcement in sleeve gastrectomy: a randomized prospective controlled study. Obes Surg. 2018;28(8):2157-2164. doi:10.1007/s11695-018-3175-2

138. Parikh M, Issa R, McCrillis A, Saunders JK, Ude-Welcome A, Gagner M. Surgical strategies that may decrease leak after laparoscopic sleeve gastrectomy: a systematic review and meta-analysis of 9991 cases. Ann Surg. 2013;257(2):231-237. doi:10.1097/ SLA.0b013e31826cc714

139. Youssef T, Abdalla E, El-Alfy K, Dawoud I, Morshed M, Farid M. Impact of botulinum neurotoxin pyloric injection during laparoscopic sleeve gastrectomy on postoperative gastric leak: a clinical randomized study. Obes Surg. 2016;26(3):494-504. doi:10.1007/s11695-015-1794-4

140. Nelson L, Moon RC, Teixeira AF, Jawad MA. Methylene blue or upper GI, which is more effective for detecting leaks in gastric bypass patients? Surg Laparosc Endosc Percutan Tech. 2015;25 (5):451-454. doi:10.1097/SLE.0000000000000191

141. Sakran N, Goitein D, Raziel A, et al. Gastric leaks after sleeve gastrectomy: a multicenter experience with 2834 patients. Surg Endosc. 2013;27(1):240-245. doi:10.1007/s00464-012-2426-x

142. Lin S, Guan W, Hans P, Liang H. Status of laparoscopic sleeve gastrectomy in China: a national survey. Obes Surg. 2017;27 (11):2968-2973. doi:10.1007/s11695-017-2727-1

143. Chouillard E, Younan A, Alkandari M, et al. Roux-en-Y fistulo-jejunostomy as a salvage procedure in patients with post-sleeve gastrectomy fistula: mid-term results. Surg Endosc. 2016;30(10):4200-4204. doi:10.1007/s00464-015-4700-1

144. McHeimeche H, Dbouk SH, Saheli R, Lichaa D, Chalaby LS. Double baltazar procedure for repair of gastric leakage post-sleeve gastrectomy from two sites: case report of new surgical technique. Obes Surg. 2018;28(7):2092-2095. doi:10.1007/ s11695-018-3241-9

145. Oshiro T, Sato Y, Nabekura T, et al. Proximal gastrectomy with double tract reconstruction is an alternative revision surgery for intractable complications after sleeve gastrectomy. Obes Surg. 2017;27(12):3333-3336. doi:10.1007/s11695-017-2935-8

146. El Chaar M, Stoltzfus J, Melitics M, Claros L, Zeido A. 30-day outcomes of revisional bariatric stapling procedures: first report based on MBSAQIP data registry. Obes Surg. 2018;28 (8):2233-2240. doi:10.1007/s11695-018-3140-0

147. Stefanidis D, Malireddy K, Kuwada T, Phillips R, Zoog E, Gersin KS. Revisional bariatric surgery: perioperative morbidity is determined by type of procedure. Surg Endosc. 2013;27 (12):4504-4510. doi:10.1007/s00464-013-3097-y

148. Shimizu H, Annaberdyev S, Motamarry I, Kroh M, Schauer PR, Brethauer SA. Revisional bariatric surgery for unsuccessful weight loss and complications. Obes Surg. 2013;23 (11):1766-1773. doi:10.1007/s11695-013-1012-1

149. Roller JE, Provost DA. Revision of failed gastric restrictive operations to Roux-en-Y gastric bypass: impact of multiple prior bariatric operations on outcome. Obes Surg. 2006;16 (7):865-869. doi:10.1381/096089206777822412

150. Nevo N, Abu-Abeid S, Hazzan D, Lahat G, Nachmani I, Eldar SM. Gastric bypass as a third bariatric procedure-our experience with 42 cases. Obes Surg. 2019;29(1):215-220. doi:10.1007/s11695-018-3503-6
151. Chiappetta S, Stier C, Scheffel O, Theodoridou S, Weiner R. The first case report of failed single-anastomosis-duodeno-ileal bypass converted to one anastomosis gastric bypass/mini-gastric bypass. Int J Surg Case Rep. 2017;35:68-72. doi:10.1016/j.ijscr.2017.04.020

152. Debs T, Petrucciani N, Gugenheim J. Why would a patient complain of dysphagia and heartburn after multiple bariatric surgeries? Gastroenterology. 2017;153(3):653-654. doi:10.1053/ j.gastro.2017.03.066

153. Umemura A, Lee WJ, Sasaki A, Wakabayashi G. History and current status of bariatric and metabolic surgeries in East Asia. Asian J Endosc Surg. 2015;8(3):268-274. doi:10.1111/ases.12190

154. Jaruvongvanich V, Wongjarupong N, Vantanasiri K, Samakkarnthai P, Ungprasert P. Midterm outcome of laparoscopic sleeve gastrectomy in asians: a systematic review and meta-analysis. Obes Surg. 2020;30(4):1459-1467. doi:10.1007/ s11695-019-04332-2

155. Park JY, Kim YJ. Laparoscopic gastric bypass vs sleeve gastrectomy in obese Korean patients. World J Gastroenterol. 2015;21 (44):12612-12619. doi:10.3748/wjg.v21.i44.12612

156. Saiki A, Yamaguchi T, Tanaka S, et al. Background characteristics and postoperative outcomes of insufficient weight loss after laparoscopic sleeve gastrectomy in Japanese patients. Ann Gastroenterol Surg. 2019;3(6):638-647. doi:10.1002/ags3.12285

157. Haruta H, Kasama K, Ohta M, et al. Long-term outcomes of bariatric and metabolic surgery in japan: results of a multi-institutional survey. Obes Surg. 2017;27(3):754-762. doi:10.1007/s11695-016-2361-3

158. Kasama K, Tagaya N, Kanehira E, et al. Laparoscopic sleeve gastrectomy with duodenojejunal bypass: technique and preliminary results. Obes Surg. 2009;19(10):1341-1345. doi:10.1007/ s11695-009-9873-z

159. Huang CK, Chhabra N, Goel R, Hung CM, Chang PC, Chen YS. Laparoscopic adjustable gastric banded plication: a case-matched comparative study with laparoscopic sleeve gastrectomy. Obes Surg. 2013;23(8):1319-1323. doi:10.1007/s11695-013-0951-x

160. Huang CK, Lo CH, Shabbir A, Tai CM. Novel bariatric technology: laparoscopic adjustable gastric banded plication: technique and preliminary results. Surg Obesity Related Dis. 2012;8 (1):41-45. doi:10.1016/j.soard.2011.03.005

161. van Rutte PWJ, Smulders JF, de Zoete JP, Nienhuijs SW. Indications and short-term outcomes of revisional surgery after failed or complicated sleeve gastrectomy. Obes Surg. 2012;22 (12):1903-1908. doi:10.1007/s11695-012-0774-1

162. Cheung D, Switzer NJ, Gill RS, Shi X, Karmali S. Revisional bariatric surgery following failed primary laparoscopic sleeve gastrectomy: a systematic review. Obes Surg. 2014;24 (10):1757-1763. doi:10.1007/s11695-014-1332-9

163. Adair MJ, Alharthi S, Ortiz J, et al. Robotic surgery is more expensive with similar outcomes in sleeve gastrectomy: analysis of the NIS database. Am Surg. 2019;85(1):39-45. doi:10.1177/ 000313481908500120

164. Magouliotis DE, Tasiopoulou VS, Sioka E, Zacharoulis D. Robotic versus laparoscopic sleeve gastrectomy for morbid obesity: a systematic review and meta-analysis. Obes Surg. 2017;27 (1):245-253. doi:10.1007/s11695-016-2444-1

165. Fazl Alizadeh R, Li S, Inaba CS, et al. Robotic versus laparoscopic sleeve gastrectomy: a MBSAQIP analysis. Surg Endosc. 2019;33(3):917-922. doi:10.1007/s00464-018-6387-6

166. Nasser H, Ivanics T, Ranjal RS, Leonard-Murali S, Genaw J. Perioperative outcomes of robotic versus laparoscopic sleeve gastrectomy in the super-obese. J Surg Res. 2020;249:34-41. doi:10.1016/j.jss.2019.12.012

167. Alqahtani A, Al-Darwish A, Mahmoud AE, Alqahtani YA, Elahmedi M. Short-term outcomes of endoscopic sleeve gastroplasty in 1000 consecutive patients. Gastrointest Endosc. 2019;89 (6):1132-1138. doi:10.1016/j.gie.2018.12.012 
168. Barrichello S, Hourneaux de Moura DT, Hourneaux de Moura EG, et al. Endoscopic sleeve gastroplasty in the management of overweight and obesity: an international multicenter study. Gastrointest Endosc. 2019;90(5):770-780. doi:10.1016/j. gie.2019.06.013

169. Fayad L, Adam A, Schweitzer M, et al. Endoscopic sleeve gastroplasty versus laparoscopic sleeve gastrectomy: a case-matched study. Gastrointest Endosc. 2019;89(4):782-788. doi:10.1016/j. gie. 2018.08 .030
170. Sharaiha RZ, Kedia P, Kumta N, et al. Initial experience with endoscopic sleeve gastroplasty: technical success and reproducibility in the bariatric population. Endoscopy. 2015;47(2):164-166. doi:10.1055/s-0034-1390773

\section{Publish your work in this journal}

Diabetes, Metabolic Syndrome and Obesity: Targets and Therapy is an international, peer-reviewed open-access journal committed to the rapid publication of the latest laboratory and clinical findings in the fields of diabetes, metabolic syndrome and obesity research. Original research, review, case reports, hypothesis formation, expert opinion and commentaries are all considered for publication. The manuscript management system is completely online and includes a very quick and fair peer-review system, which is all easy to use. Visit http://www.dovepress.com/testimonials.php to read real quotes from published authors. 